\title{
Extensive linear verrucous epidermal nevus involving the right upper limb and palm
}

Keywords: asymptomatic hyperkeratotic, hyper pigmented, warty plaques, verrucous plaques, abnormalities seen, Histopathological diagnosis, epidermal nevus, Microscopic picture, papillomatosis, acanthosis, Pseudohorn cysts, psoriasis, Epidermal nevi, Neutrophilic pustulation

Abbreviations: ILVEN, Inflammatory linear verrucous epidermal nevus; LVEN, linear verrucous epidermal nevus

\section{Case presentation}

A 13 year old female, born of non-consanguineous marriage, presented with asymptomatic hyperkeratotic, hyper pigmented warty plaques distributed in a linear fashion over the right side of the body. The patient's mother complained that these lesions were present since infancy. They were stable for a long period of time, but had progressed in size to involve the whole of right upper extremity over the past 3 years. On physical examination, patient had well-defined, hyper pigmented verrucous plaques in a linear blashkoid distribution extending from just above the supramammary area, shoulder, right arm and forearm extending in a contiguous fashion to involve the thinner eminence of right palm and till the tip of index finger with some areas of intervening normal skin. There was no evidence of any other skin lesions and hair, nail, and mucosae were normal (Figure 1). The child was developmentally normal and there were no gross abnormalities seen Figure 2. A detailed systemic examination revealed no abnormality. Ophthalmologic, neurological and orthopaedic specialist consultations were sought to rule out an epidermal nevus syndrome and there was no abnormality detected in any of the systems. Microscopic picture of the biopsy showed an epidermal proliferative lesion (Figure 3). There was hyperkeratosis, papillomatosis, acanthosis and increased basal layer pigmentation. Dermal collagen and a few telangiectatic vessels were seen within the papillary projections along with mild inflammatory infiltrate. Pseudohorn cysts were also seen. Histopathological diagnosis was consistent with linear verrucous epidermal nevus (LVEN). Inflammatory linear verrucous epidermal nevus (ILVEN) shows a characteristic histological feature of regular alteration of slightly raised parakeratotic areas without a granular layer and a slightly depressed orthokeratotic area with prominent granular layer and hence was ruled out. ${ }^{1,2}$ LVEN resembles seborrheic keratosis which generally lacks the inflammatory changes and characteristic changes in the stratum corneum seen in LVEN.

In psoriasis, distinction can be difficult without clinical correlation. Neutrophilic pustulation is generally not a feature of LVEN. Epidermal nevi represent Blaschkoid hamartomas of the skin that result from mosaic post-zygotic mutations. ${ }^{3} \mathrm{LVEN}$ are the most common amongst these epidermal nevi that include nevus comedonicus, ILVEN and nevus sebaceous. ${ }^{4}$ LVEN can exist as single or multiple lesions, may be of any size and may occur on any site. ${ }^{5}$ Clinically, they appear as brownish to skin coloured, well demarcated, verrucous papules that coalesce into plaques. The majority of epidermal nevi are either present at birth or occur within the first year of life. ${ }^{4}$ LVEN pose a therapeutic challenge because superficial destruction may result in recurrence, whereas deeper modalities are limited by the extent of affected areas
Volume 2 Issue 2 - 2018

\author{
Shikhar Ganjoo,' Sweta, ${ }^{2}$ MPS Sawhney,' \\ Uma Sharma \\ 'Department of Dermatology \& SGT Medical College, Hospital \\ and Research Institute, Gurgaon \\ ${ }^{2}$ Department of Pathology, College and Hospital and Research \\ Institute, India
}

Correspondence: Shikhar Ganjoo, Department of Dermatology \& STD, Assistant Professor, SGT Medical College, Hospital and Research Institute, Gurgaon Tel 0124-2278183, Email shikhar.ganjoo@gmail.com

Received: October 30, 2017 | Published: April 25, 2018

and a higher risk of post-procedural scars. ${ }^{6,7}$ Various light-based treatments, which include Argon, ${ }^{8}$ PDT, ${ }^{9}$ ruby laser, ${ }^{10}$ Erbium:YAG, ${ }^{11}$ and $\mathrm{CO}_{2}$ laser $^{8-14}$ have been reported to be variably effective in LVEN. Extent of lesional hyperkeratosis may be a predictor of response to laser therapy. For hard or keratotic LVEN, $\mathrm{CO}_{2}$ laser was shown to be more effective than the Argon laser. ${ }^{8}$ In a study of 25 patients with epidermal nevi (24 patients with $\mathrm{LVEN}$ ), $\mathrm{CO}_{2}$ laser vaporization led to complete or almost complete resolution in $92 \%$ of patients with soft flattened nevi but only in $33 \%$ of patients with keratotic nevi. The majority of recurrent lesions occurred in patients with keratotic nevi. Of those treated, $12.5 \%$ had hypertrophic scars. ${ }^{14}$

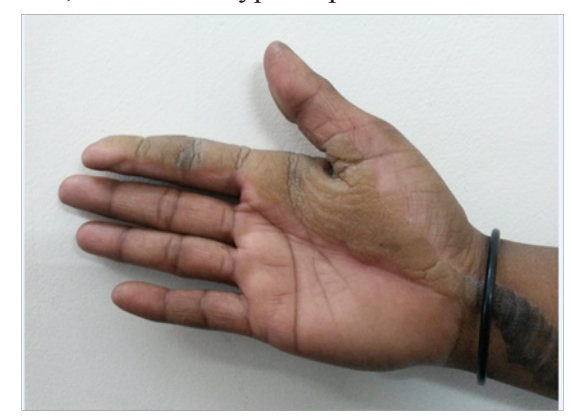

Figure I There was no evidence of any other skin lesions and hair, nail, and mucosae were normal.

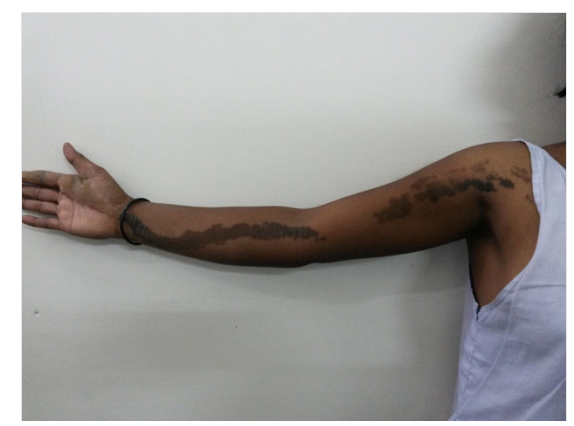

Figure 2 Shows involvement of the entire arm and chest and the extent of involvement. 


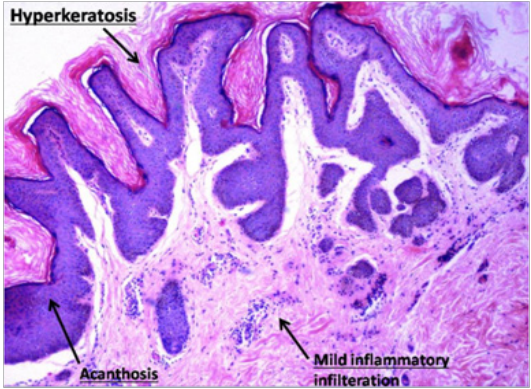

Figure 3 Microscopic picture of the biopsy showed an epidermal proliferative lesion.

\section{Acknowledgements}

None.

\section{Conflict of interest}

The authors declare there is no conflict of interest.

\section{References}

1. Pierson D, Bandel C, Ehrig T, et al. Benign epidermal tumors and proliferations. In: Bolognia JL, et al. editors. Dermatology. Philadelphia: Mosby; 2003:1697-1720.

2. Su WP. Histopathologic varieties of epidermal nevus. A study of 160 cases. Am J Dermatopathol. 1982;4(2):161-170.

3. Paller AS et al. Genetic and clinical mosaicism in a type of epidermal nevus. N Engl J Med. 1994;331(21):1408-1415.
4. Rogers M, McCrossin I, Commens C. Epidermal nevi and the epidermal nevus syndrome: a review of 131 cases. $J$ Am Acad Dermatol. $1989 ; 20(3): 476-488$

5. Shafi M. Extensive verrucous epidermal naevus. J Eur Acad Dermatol Venereol. 2001;15:269-270.

6. Adams BB, Mutasim DF. Adult onset verrucous epidermal nevus. J Am Acad Dermatol. 1999;4(5 Pt 2):824-826.

7. Alam M, Arndt KA. A method for pulsed carbon dioxide laser treatment of epidermal nevi. J Am Acad Dermatol. 2002;46(4):554-556.

8. Hohenleutner U, Landthaler M. Laser therapy of verrucous epidermal naevi. Clin Exp Dermatol. 1993;18(2):124-127.

9. Sim JH. Verrucous epidermal nevus successfully treated with photodynamic therapy. Eur J Dermatol. 2010;20:814-15.

10. Baba T, Narumi H, Hanada K, et al. Successful treatment of dark-coloured epidermal nevus with ruby laser. J Dermatol. 1995;22(8):567-570.

11. Park JH, Hwang ES, Kim SN, et al. Er:YAG laser treatment of verrucous epidermal nevi. Dermatol Surg. 2004;30(3):378-381.

12. Boyce S, Alster TS. CO2 laser treatment of epidermal nevi: long-term success. Dermatol Surg. 2002;28(7):611-614.

13. Thual N, Chevallier JM, Vuillamie $\mathrm{M}$, et al. Laser $\mathrm{CO}_{2}$ continudans le traitment des hamartomas épidermiques verruqueux. Ann Dermatol Venereol. 2006;133(2):131-132.

14. Paradela $\mathrm{S}$ et al. Epidermal nevi treated by carbon dioxide laser vaporization: a series of 25 patients. J Dermatolog Treat. 2007;18:169174. 